Konstanzer Online-Publikations-System (KOPS)

URL: http://www.ub.uni-konstanz.de/kops/volltexte/2007/4244/

URN: http://nbn-resolving.de/urn:nbn:de:bsz:352-opus-42440

\title{
Detection of Charge Movements in Ion Pumps by a Family of Styryl Dyes
}

\author{
M. Pedersen, ${ }^{1}$ M. Roudna, ${ }^{1}$ S. Beutner, ${ }^{2}$ M. Birmes, ${ }^{2}$ B. Reifers, ${ }^{2}$ H.-D. Martin, ${ }^{2}$ H.-J. Apell ${ }^{1}$ \\ ${ }^{1}$ Department of Biology, University of Konstanz, Fach M635, 78457 Konstanz, Germany \\ ${ }^{2}$ Institute for Organic Chemistry and Macromolecular Chemistry, University of Düsseldorf, 40225 Düsseldorf, Germany
}

Received: 25 May 2001/Revised: 29 September 2001

Abstract. A family of fluorescent styryl dyes was synthesized to apply them as probes that monitor the ion-translocating activity of the $\mathrm{Na}, \mathrm{K}$-ATPase and the SR Ca-ATPase, similar to the widely used dye RH421. All dyes had the same chromophore but they differed in the length of the spacer between chromophore and polar head, an isothiocyanate group, and in the lengths of the two identical acyl chains, which form the tail of the dye molecules. A number of substrate-dependent partial reactions of both P-type ATPases affected the fluorescence intensity, and the magnitude of the fluorescence changes was used to characterize the usefulness of the dyes for further application. The experimental results indicate that electrochromy is the major mechanism of these dyes. While in the case of the Na,K-ATPase a single dye, 5QITC, showed larger fluorescence changes than all others, in the case of the SR Ca-ATPase all dyes tested were almost equal in their fluorescence responses. This prominent difference is interpreted as a hint that the position of the ion binding sites in both ion pumps may differ significantly despite their otherwise closely related structural features. Quench experiments with spin-labeled lipids in various positions of their fatty acids were used to gain information on the depth of the chromophore of the different dyes within the membrane dielectric, however, the spatial resolution was so poor that only qualitative information on the position of the chromophore in the lipid phase could be obtained.

Key words: P-type ATPases - Ion binding sites Electrochromic effects - Styryl dyes - Fluorescence - Partial reactions

\section{Introduction}

Detailed investigations of the ion-transport process in P-type ATPases have revealed pump cycles in which the ions are moved across the membranes by several reaction steps. Most of these pumps transfer different ions in opposite directions, such as $\mathrm{Na}^{+}$vs. $\mathrm{K}^{+}, \mathrm{H}^{+}$, vs. $\mathrm{K}^{+}$or $\mathrm{Ca}^{2+}$ vs. $\mathrm{H}^{+}$, and in all these cases the process is a so-called Ping-Pong mechanism (Läuger, 1991). Each "half cycle" consists of an ordered sequence of experimentally identified steps: ion binding, ion occlusion (together with enzyme phosphorylation or dephosphorylation), transition between both principal conformations, $E_{1} \rightarrow E_{2}$ or vice versa, ion deocclusion and release to the aqueous phase on the other side of the membrane. In principle, the ions could be moved through the interior of the protein dielectric to a certain extent at each of these steps; however, recent investigations revealed that a charge movement occurred mainly during the ion binding and release steps (Apell, Schneeberger \& Sokolov, 1998; Butscher, Roudna \& Apell, 1999; Apell \& Karlish, 2001). Those reaction steps are termed "elctrogenic" (Läuger \& Apell, 1989; Apell, 1989).

To detect and to analyze such reaction steps, experimental techniques are necessary, which allow a resolution of the charge movement in time and amplitude. In the case of the Na,K-ATPase, during the last decade two different approaches were applied, which both produced kinetical information on electrogenic partial reactions. The first approach made use of direct electric measurements, either by electrophysiological techniques applied to native cells (Rakowski et al., 1990, Gadsby, Rakowski \& De Weer, 1993; Rakowski, 1993; Hilgemann, 1994; Holmgren et al., 2000) or by use of capacitive coupling of open membrane fragments purified from kidney tissue, which were adsorbed tightly to planar lipid bilayers (Fendler et al., 1985; Borlinghaus, Apell \& Läuger, 1987; Wuddel \& Apell, 1995; Sokolov et al., 1998; 
Pintschovius, Fendler \& Bamberg, 1999; Domaszewicz \& Apell, 1999). As an alternative method an indirect approach was introduced, which utilizes electrochromic styryl dyes that allow the detection of charge movements in the Na,K-ATPase (Klodos \& Forbush, III, 1988; Bühler et al., 1991; Stürmer et al., 1991; Pratap \& Robinson, 1993; Heyse et al., 1994; Fedosova, Cornelius \& Klodos, 1995; Klodos, Fedosova \& Cornelius, 1997; Clarke et al., 1998; Schneeberger \& Apell, 1999). In the case of the CaATPase of the sarcoplasmatic reticulum (SR) the situation is different: direct electric measurements are not possible since the membrane of the SR is extremely leaky for monovalent cations, a property that short-circuits both sides of the membrane. Therefore, investigations to identify and analyze the electrogenic reaction steps with native membranes containing the SR Ca-ATPase so far could be performed successfully only with the use of styryl dyes (Butscher et al., 1999; Peinelt \& Apell, 2002). Originally, styryl dyes were used to monitor fast changes of transmembrane electric potentials (Loew et al., 1979; Loew \& Simpson, 1981; Loew, 1982; Grinvald et al., 1983, 1987; Ehrenberg, Meiri \& Loew, 2000). The proposed mechanism of the styryl dyes is based mainly on the effect of electrochromy, by which changes of the (local) electric field inside the membrane dielectric shift the absorption spectra and thus affect the fluorescence yield when the chromophore is excited at a wavelength preferentially at the red edge of its absorption spectrum (Loew et al., 1979; Fluhler et al., 1985; Bühler et al., 1991). Besides the electrochromic shift of the absorption spectrum of styryl dyes, their voltage response may depend on additional components, which also affect the excitation process of the dye molecules, as was discussed by several authors (Fluhler et al., 1985; Müller, Windisch \& Tritthart, 1986; Ephardt \& Fromherz, 1989; Fedosova et al., 1995).

The styryl dye molecules are strongly hydrophobic with partition coefficients $\gamma=c_{\text {lipid }} / c_{\text {water }}>10^{5}$ (see below), they have an amphiphilic nature and are statistically distributed within the lipid leaflet of the membrane. Due to the polar head group and the hydrophobic chromophore and tail the dye molecules are inserted in an oriented fashion with the polar or charged head sticking in between the lipid head groups and the alkyl chains in between the hydrophobic core of the lipids.

To study charge-translocating reaction steps in the reaction sequence of an ion pump with such electrochromic dyes, it is crucial to have a high density of proteins in the membrane, in which the number or position of ionic charges inside the transmembrane proteins is changed by the transport process. This requirement can be explained by basic physical principles. On the one hand, the electrochromic effect of a fluorescent dye is proportional to

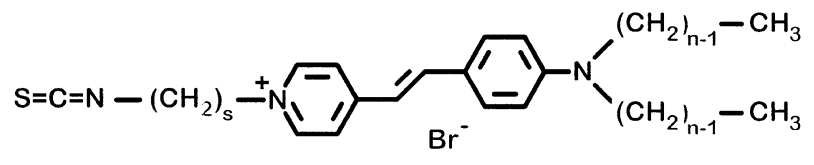

Fig. 1. Principal structure of the fluorescent styryl dyes of the $n$ XITC family. The spacer length between the polar isothiocyanate group and the chromophore, $\left(\mathrm{CH}_{2}\right)_{\mathrm{s}}$, was chosen between 3 and 6 , and is represented by the first letter of its name: PITC $(s=3)$, BITC $(s=4)$, QITC $(s=5)$, HTTC $(s=6)$. The hydrophobic tail consists of two alkyl chains with $n$ carbons, $1 \leq n \leq 7$. The length of the chain is indicated by the number in front of the letters.

the electric field it senses. On the other hand, if we, for the sake of simplicity, treat the protein-containing membranes as a plate capacitor with a homogeneous and low dielectric constant, $\varepsilon$ (in the order of 2-4), the electric field is proportional to the charge density, $\sigma$. The more protein molecules per membrane area bind or release ions, the greater is the change of $\sigma$, the larger is the change of the electric field, and, in consequence, the stronger is the response of the fluorescent dyes. Under the assumption of a homogeneous membrane with a thickness of $5 \mathrm{~nm}$, a dielectric constant $\varepsilon=3$, and a pump density of 10,000 pumps per $\mu \mathrm{m}^{2}$, the charge density $\sigma$ would be $1.6 \times 10^{-3} \mathrm{C} /$ $\mathrm{m}^{2}$. The corresponding amplitude of the electric field is then calculated to be $E=6 \times 10^{7} \mathrm{~V} / \mathrm{m}$. This is about three times the amplitude of the electric field generated by a transmembrane potential of $100 \mathrm{mV}$.

Various fluorescent styryl dyes produced different responses in different membrane/ion pump systems. The chromophore itself as well as the hydrophobic tail and the spacer between the chromophore and polar "head" of the dye are known to affect the sensitivity of the fluorescence response on charge-translocating reaction steps of the ion pumps (Fedosova et al., 1995, Butscher et al., 1999). This observation led to the conception of this paper to study systematically the effect of charge movements produced by the action of the $\mathrm{Na}, \mathrm{K}-\mathrm{ATPase}$ and the Ca-ATPase on the fluorescence responses of a family of styryl dyes, named $n X I T C$, with various lengths of the hydrophobic tail and of the spacer between polar head and chromophore (Fig. 1).

\section{Materials and Methods}

Phosphoenolpyruvate, pyruvate kinase, lactate dehydrogenase, NADH, ATP (disodium salt, special quality) were from Boehringer (Mannheim, Germany). Tricine and TEMPO (2,2,6,6-Tetramethylpiperidine-N-oxyl) were purchased from Sigma (Munich, Germany). Sodium dodecylsulfate (SDS) was obtained from Pierce Chemical (Rockford, IL). Dioleoylphosphatidyl choline (DOPC), TEMPO-PC and 5-, 7-, 10-, 12-, and 16-doxyl-1-palmitoyl-2-stearoyl-sn-glycero-3-phosphocholine were purchased from Avanti Polar Lipids, Alabaster, Ala. RH 421 ( $N$-(4-sulfobutyl)-4(4-(4-(dipentylamino) phenyl-butadienyl-pyridinium, inner salt), 
Table 1. UV/VIS data of the synthesized isothiocyanate dyes, nXITC, dissolved in EtOH

\begin{tabular}{|c|c|c|c|c|c|c|c|c|}
\hline \multirow[t]{2}{*}{$\mathrm{X}$} & \multirow[t]{2}{*}{$s$} & \multicolumn{7}{|c|}{$\lambda_{\max } / \mathrm{nm}\left(\varepsilon / 10^{3} \mathrm{M}^{-1} \mathrm{~cm}^{-1}\right)$} \\
\hline & & $\begin{array}{l}\mathrm{R}=\mathrm{CH}_{3} \\
n=1\end{array}$ & $\begin{array}{l}\mathrm{C}_{2} \mathrm{H}_{5} \\
n=2\end{array}$ & $\begin{array}{l}\mathrm{C}_{3} \mathrm{H}_{7} \\
n=3\end{array}$ & $\begin{array}{l}\mathrm{C}_{4} \mathrm{H}_{9} \\
n=4\end{array}$ & $\begin{array}{l}\mathrm{C}_{5} \mathrm{H}_{11} \\
n=5\end{array}$ & $\begin{array}{l}\mathrm{C}_{6} \mathrm{H}_{13} \\
n=6\end{array}$ & $\begin{array}{l}\mathrm{C}_{7} \mathrm{H}_{15} \\
n=7\end{array}$ \\
\hline $\mathrm{P}$ & 3 & $490(45.1)$ & $504(50.9)$ & $504(53.7)$ & $505(52.7)$ & $506(38.0)$ & $499(30.2)$ & $506(30.7)$ \\
\hline B & 4 & $488(44.2)$ & $500(48.6)$ & $502(50.8)$ & $503(52.5)$ & $503(47.0)$ & $496(26.0)$ & $503(46.4)$ \\
\hline Q & 5 & $487(39.8)$ & $499(50.2)$ & $498(54.3)$ & $501(54.9)$ & $501(41.7)$ & $496(26.9)$ & $502(33.7)$ \\
\hline $\mathrm{H}$ & 6 & $485(49.0)$ & $498(49.7)$ & $500(54.4)$ & $500(56.5)$ & $500(49.0)$ & $496(28.6)$ & $500(30.7)$ \\
\hline
\end{tabular}

EGTA and Bis-Tris (Bis(2-hydroxyethyl)amino-tris (hydroxymethyl) methane) were obtained from Fluka (Buchs, Switzerland). $\mathrm{NaCl}$ (suprapure quality) and all other reagents (at least analytical grade) were from Merck (Darmstadt, Germany).

\section{Preparation of Membrane Fragments Containing Na, K-ATPase}

$\mathrm{Na}, \mathrm{K}-\mathrm{ATPa} e$ was prepared from the outer medulla of rabbit kidneys in the form of open membrane fragments using procedure C of Jørgensen (Jørgensen, 1974). The protein concentration was assessed by the Lowry method, using bovine serum albumin as a standard. Specific ATPase activity was determined by the pyruvate kinase/lactate dehydrogenase assay (Schwartz et al., 1971). The specific activity of the preparations used was in the range of 1,900 to $2,300 \mu \mathrm{M} \mathrm{P}_{\mathrm{i}}$ per $\mathrm{mg}$ protein and hr at $37^{\circ} \mathrm{C}$.

\section{Preparation of Sarcoplasmic Reticulum Mem- BRANES Containing Ca-ATPase}

SR-Ca-ATPase was prepared by a slight modification of the method of Heilmann et al. (1977) from psoas muscle of rabbits. The whole procedure was performed at temperatures below $4^{\circ} \mathrm{C}$. The determination of the protein content of the membrane preparation was performed according to Markwell et al. (1978). The most active fractions of the final density-gradient separation had a protein content of $2-3 \mathrm{mg} / \mathrm{ml}$. The enzymatic activity was determined by the linked pyruvate kinase/lactate dehydrogenase assay (Schwartz et al., 1971) in a buffer containing $2 \mu \mathrm{M}$ of free $\mathrm{Ca}^{2+}$. Background enzymatic activity of the isolated preparation was obtained by either quantitative removal of the free $\mathrm{Ca}^{2+}$ by $5 \mathrm{~mm}$ EGTA or addition of $1 \mu \mathrm{M}$ tharpsigargin. The Ca-ATPase-specific activity was about 1.8 units $/ \mathrm{mg}$ at $20^{\circ} \mathrm{C}$ and $\mathrm{pH} 7.5$ (which corresponds to $1.8 \mu \mathrm{mol}$ ATP hydrolyzed per $\mathrm{mg}$ protein per min) and could be increased up to 2.6 units/mg in the presence of A23187 to short-circuit the membranes for $\mathrm{Ca}^{2+}$.

\section{Synthesis of The Family of Styryl Dyes}

The styryl dyes were prepared by the following general procedure (Hassner et al., 1984; Birmes, 1995): A mixture of 4-bromo- $N, N$-di$n$-alkylaniline $(22.5 \mathrm{mmol}), 4$-vinylpyridine $(30 \mathrm{mmol})$, palladium diacetate $(0.45 \mathrm{mmol})$, and tri-o-tolylphosphine $(0.9 \mathrm{mmol})$ in dry triethylamine $(18 \mathrm{ml})$ was heated at $110^{\circ} \mathrm{C}$ for $72 \mathrm{hr}$ under argon. Water $(200 \mathrm{ml})$ and chloroform $(300 \mathrm{ml})$ were added to the cooled mixture. The chloroform phase was separated and the water layer was extracted with chloroform $(3 \times 50 \mathrm{ml})$. The combined chloroform solutions were washed with water, dried over $\mathrm{MgSO}_{4}$ and evaporated to give the 4 -( $p$ - $N, N$-di- $n$-alkylamino)-styrylpyridine. Purification of the product was carried out by recrystallization from an appropriate solvent (e.g., $n$-pentane).

A solution of 4-( $p$ - $N, N$-dialkylamino)-styrylpyridine ( $3 \mathrm{mmol})$ and $\omega$-bromo- $n$-alkyl-isothiocyanate $(9 \mathrm{mmol})$ in dry acetone $(2 \mathrm{ml})$ was refluxed. The quaternization progress was monitored by thin layer chromatography (TLC) using chloroform as eluent. After completed conversion the red solid was separated and recrystallized from acetone $/ n$-hexane. The products were identified by ${ }^{1} \mathrm{H}-\mathrm{NMR}$ spectroscopy and IR spectroscopy. The IR spectra of all dyes show the characteristic $n(\mathrm{~N}=\mathrm{C}=\mathrm{S})$ band at $2200-2000 \mathrm{~cm}^{-1}$. The purity was checked by TLC.

The $\omega$-bromo- $n$-alkyl-isothiocyanates were synthesized using a procedure by P. Friis (1965): $\omega$-Bromo- $n$-alkylamine hydrobromide (171 mmol) was treated with thiophosgen $(170 \mathrm{mmol})$ in chloroform $(80 \mathrm{ml})$ and triethylamine $(600 \mathrm{mmol})$ and was then isolated by distillation under reduced pressure.

The spectroscopic data of the resulting dyes are shown in Table 1.

\section{FLuORESCENCE EXPERIMENTS}

Fluorescence measurements were performed with a commercial fluorescence spectrometer LS 50B (Perkin Elmer, Überlingen, Germany) with quartz cuvettes of 1 or $2 \mathrm{ml}$ effective volume. A 515 nm cut-off filter in the emission pathway was used for all measurements. The cuvette holder was thermostated at $20^{\circ} \mathrm{C}$ and equipped with a magnetic stirrer. Experiments to study ion-pump specific responses with the styryl dyes were performed as so-called standard experiments, which were described previously in the case of Na, K-ATPase (Schneeberger \& Apell, 1999) and of SR CaATPase (Butscher et al., 1999). In a first set of experiments, the excitation wavelength dependence of the fluorescence signals was recorded in steady-state conditions of the $\mathrm{Na}$, K-ATPase and of the Ca-ATPase, which could be maintained by defined substrate compositions of the ion pumps. In a second set of such experiments, the time course of the fluorescence intensity was investigated at the optimum wavelength combination for excitation and emission, and the fluorescence changes of well-defined partial reactions were detected, which could be triggered by successive addition of substrates. The concentration of the dyes applied was typically 200 nм. The excitation and the emission wavelengths for the applied dyes are listed for both ion pumps in Tables 3 and 4 . The slit widths were 5 or $7.5 \mathrm{~nm}$ for the excitation and 10 or $15 \mathrm{~nm}$ for the emission monochromator.

\section{Determination of Partition Coefficient of THE STYRYL Dyes}

Lipid vesicles were prepared from synthetic dioleoylphosphatidyl choline (DOPC) by a dialysis method producing homogeneous unilamellar vesicles with an average diameter of about $80 \mathrm{nM}$ as described previously (Apell et al., 1985). The membrane-water partition coefficient, $\gamma$, of the dye is defined by $\gamma=c_{1} / c_{\mathrm{w}}$, where $c_{1}$ and $c_{\mathrm{w}}$ are the respective dye concentration in the lipid phase and water phase. The experiments were performed as described previously (Apell \& Bersch, 1987). 
Table 2. Partition coefficients of selected nXITC dyes determined with DOPC vesicle preparations

\begin{tabular}{|c|c|c|c|c|c|}
\hline \multirow[t]{2}{*}{$\mathrm{X}$} & \multirow[t]{2}{*}{$s$} & \multicolumn{4}{|c|}{ Partition coefficient $\gamma=c_{\text {lipid phase }} / c_{\text {water phase }}$} \\
\hline & & $\begin{array}{l}\mathrm{C}_{2} \mathrm{H}_{5} \\
n=2\end{array}$ & $\begin{array}{l}\mathrm{C}_{4} \mathrm{H}_{9} \\
n=4\end{array}$ & $\begin{array}{l}\mathrm{C}_{5} \mathrm{H}_{11} \\
n=5\end{array}$ & $\begin{array}{l}\mathrm{C}_{7} \mathrm{H}_{15} \\
n=7\end{array}$ \\
\hline $\mathrm{P}$ & 3 & 38,000 & 284,000 & 336,000 & \\
\hline B & 4 & 45,000 & 544,000 & 654,000 & $1,614,000$ \\
\hline Q & 5 & 45,000 & 711,000 & 804,000 & \\
\hline $\mathrm{H}$ & 6 & & & 638,000 & $1,716,000$ \\
\hline
\end{tabular}

\section{Preparation of Lipid Vesicles Containing Doxyl Labels and Styryl Dyes}

Vesicles for quenching experiments were prepared by sonification. They were composed of lipid (either $100 \%$ DOPC or $85 \%$ DOPC and $15 \%$ of one of the spin-labeled phospholipids) and $200 \mathrm{~mm}$ of one of the styryl dyes. Lipids and dyes were dissolved in organic solvent (ethanol, methanol and chloroform for dyes, DOPC, and spin-labeled lipids, respectively). Dye, DOPC, and spin-labeled lipid were added into a test tube, and the organic solvents were evaporated under a flow of argon. Afterwards, the samples were dried in vacuum for 45 minutes. Then $2 \mathrm{ml}$ buffer $(25 \mathrm{~mm}$ histidine, $100 \mathrm{~mm} \mathrm{NaCl}, 5 \mathrm{~mm} \mathrm{MgCl}_{2}$, and $0.5 \mathrm{~mm}$ EDTA, pH 7.2) were added, and the samples were sonicated for 3 minutes in an ultrasonication bath (Transsonic Digital, Elma, Singen, Germany).

During sonication the samples were kept under a constant flow of argon to prevent oxidation. The final lipid concentration of the samples was checked by the Phospholipids B test (Wako Chemicals, Neuss, Germany) to be $60 \mu \mathrm{m}$ pure DOPC or DOPC with $15 \%$ spin-labeled phospholipid. With a dye concentration of $200 \mathrm{nM}$, the (molar) lipid/dye ratio was 300:1.

\section{EPR Measurements to Determine the Concentration of Doxyl Labels}

For the accuracy of the quench experiments it was crucial to maintain a constant concentration of the quenching spin labels and of the same ratio of dye/lipid/spin label in all vesicle preparations. To determine the concentration of spins in the labeled lipids, EPR analysis was performed. The intensities of the doubly integrated EPR spectra of the doxylated phospholipids were compared to those of a defined TEMPO standard. Duplicate samples of spin-labeled lipids dissolved in DMSO were prepared. The EPR spectrometer was calibrated with TEMPO samples at concentrations between 80 and 400 $\mu \mathrm{M}$ in DMSO. The samples were pipetted into $100 \mu \mathrm{l}$ capillaries sealed with sealing wax (Critoseal, Oxford Labware, Chicago, IL) and placed in the sample cavity of a Varian E 109 spectrometer (Varian, Darmstadt, Germany). The microwave power was $2 \mathrm{~mW}$ in order to avoid signal saturation, the magnetic field was scanned between 3325 and 3425 Gauss, and the detector current was $250 \mu \mathrm{A}$. The spectra were analyzed with the computer program "EPR" by Frank Neese, University of Konstanz, and the values of the doubly integrated spectra were used to determine the spin concentration. The ratios of the spin/lipids in the purchased stock solutions of spinlabeled phospholipids were found to be in the range of 0.75 to 0.95 .

The concentration of TEMPO-PC was checked by a phosphate assay (Bartlett, 1959) subsequent to total digestion of the lipid (Morrison, 1964).

\section{Fluorescence Quench Experiments}

Duplicate samples of ten selected dyes in vesicles of pure DOPC and of $85 \%$ DOPC and $15 \%$ of each of the spin-labeled lipids were investigated. Two-ml samples of the sonicated solutions were pipetted into cuvettes and placed in the cuvette holder of a Perkin Elmer LS 50 B fluorescence spectrometer. The samples were measured at excitation and emission slit widths of $5 \mathrm{~nm}$ respectively, except for 1 QITC and 2QITC. These dyes showed very small fluorescence signals and were measured with both slits set to $7.5 \mathrm{~nm}$. A $515-\mathrm{nm}$ cut-off filter in the emission pathway was used for all measurements. The fluorescence was recorded in the excitation and emission maximum of each dye as given in Table 3.

Since an initial redistribution process of lipid and dye molecules between vesicles, aqueous buffer and cuvette walls took place after filling the vesicle suspension into a clean cuvette, the initial fluorescence decreased at the beginning of a 15-min long reading. This process could be represented by a mono- or biexponential decay and could be reproduced by the function $F(t)$ $=\Delta F_{1} \exp \left(-t / \tau_{1}\right)+\Delta F_{2} \exp \left(-t / \tau_{2}\right)+F_{\mathrm{SS}}$, where $F$ is the detected fluorescence, $t$ the time in seconds. $\Delta F_{1}$ and $\Delta F_{2}$ are the amplitudes of fluorescence decreases, $\tau_{1}$ and $\tau_{2}$ are the life times of this process. The second exponential was a (minor) instrumental artifact with $\tau_{2}>700 \mathrm{sec}$ and could be observed only in a few experiments. For comparison of the quenching effects of the doxyl labels on the styryl dyes the steady-state fluorescence level, $F_{\mathrm{SS}}$, was used. The magnitude of quenching was determined as quench ratio, $Q=F_{\mathrm{SS}}(+$ spin label $) / F_{\mathrm{SS}}(-$ spin label $)$, for each of the styryl dyes and quenchers.

\section{Results}

The original intention of the application of the synthesized fluorescent isothiocyanate dyes (Fig. 1) was to link them by their $\mathrm{S}=\mathrm{C}=\mathrm{N}$-group covalently to an ion pump, as it has been performed with FITC (fluoresceine 5-isothiocyanate) before (Karlish, 1980), and to overcome by such a specific labeling the necessity of membrane preparations with high densities of pump proteins, which is an inevitable prerequisite for the investigations when the dye molecules are evenly distributed in the membrane, as has been explained in the Introduction. However, with all members of the $n$ XITC dyes tested, independent of the length of the spacer between the polar isothiocyanate head group and the chromophore, it was impossible to obtain a (covalent) linkage between proteins and dyes. We propose that the main reason for this failure is the high partition coefficients of the dyes (Table 2), which led to a fast redistribution of the dye into the lipid phase of the membranes when both, dye and membranes, were 

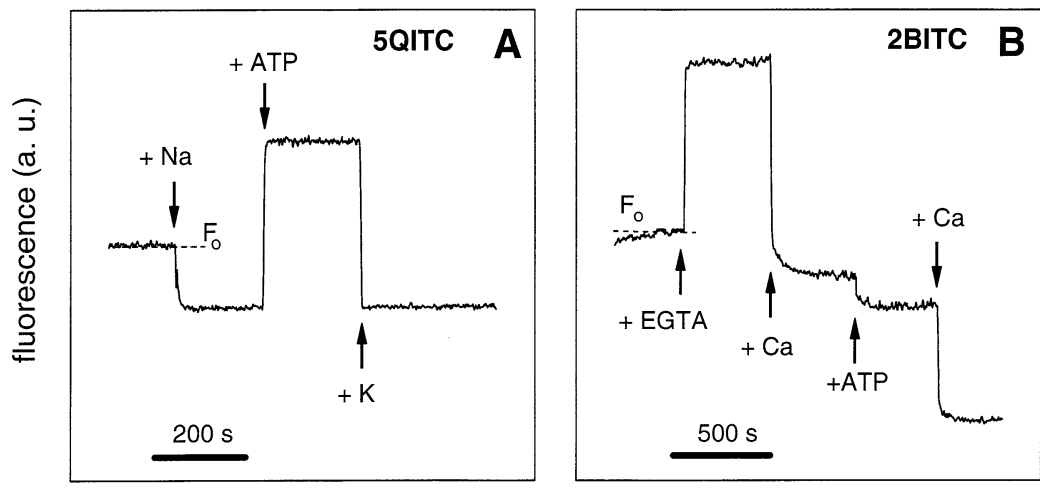

Fig. 2. Investigation of electrogenic partial reactions of the $\mathrm{Na}, \mathrm{K}-$ ATPase and the SR Ca-ATPase with electrochromic styryl dyes by so-called standard experiments. $(A)$ The electrochromic reaction steps that could be detected in the case of $\mathrm{Na}, \mathrm{K}$-ATPase and dye 5QITC. The detectable steps were cytoplasmic binding of $\mathrm{Na}^{+}$ions $(+N a), E_{1}+3 \mathrm{Na}_{\text {cyt }}^{+} \rightarrow \mathrm{Na}_{3} E_{1}$, when $50 \mathrm{~mm} \mathrm{NaCl}$ were added to buffer containing neither $\mathrm{Na}^{+}$nor $\mathrm{K}^{+}$ions. Addition of $0.5 \mathrm{~mm}$ ATP induced the next sequence of steps (+ ATP), $\mathrm{Na}_{3} E_{1}+\mathrm{ATP} \rightarrow \ldots \rightarrow \mathrm{P}-E_{2}+3 \mathrm{Na}_{\text {ext }}^{+}+\mathrm{ADP}$. The third step $(+$ $K$ ) contains, after addition of $20 \mathrm{~mm} \mathrm{KCl}$, binding of $\mathrm{K}^{+}$ions to the $\mathrm{P}-E_{2}$ state and the beginning of a continuous turnover,

mixed in an aqueous solution. A partition coefficient of $>10^{4}$ corresponds to the fact that more than $99.99 \%$ of the dye molecules are in the lipid phase. Under this condition the range and the degree of freedom of the isothiocyanate group were not high enough to find an appropriate lysine on the protein surface of the ion pumps to react with independently of the length of the spacer. However, even without the chemical linkage these electrochromic dyes exhibited a number of properties that make them useful for further applications, at least for experiments with membranes containing $\mathrm{Na}, \mathrm{K}$-ATPase and the SR Ca-ATPase and, perhaps, also with other ion pumps.

The fluorescence response of the $n$ XITC dyes to an addition of negatively and positively charged hydrophobic ions, $\mathrm{TPB}^{-}$and $\mathrm{TPP}^{+}$, was in full agreement with the findings observed with RH421 earlier (Bühler et al., 1991). These experiments were performed with lipid vesicles, purified membrane preparations containing $\mathrm{Na}, \mathrm{K}-\mathrm{ATPase}$, and $\mathrm{Ca}-$ ATPase-containing membranes from SR (not shown). Titration experiments with the Ca-ATPase in state $E_{1}$ with $\mathrm{Ca}^{2+}, \mathrm{Mg}^{2+}$ and $\mathrm{H}^{+}$ions, demonstrated that the ion binding and release steps are detected by $n$ XITC (Peinelt \& Apell, 2002). This is also supported by experiments in which in the absence of $\mathrm{Ca}^{2+}$ and $\mathrm{Mg}^{2+}$ ions, when a considerable amount of the ion pumps is expected to be in state $E_{2}\left(\mathrm{H}_{2}\right)$, ATP was added. The shift of the equilibrium from $E_{2}$ into state $E_{1}$ was not accompanied by a change in the fluorescence level (not shown).
$\mathrm{P}-E_{2}+2 \mathrm{~K}_{\mathrm{ext}}^{+} \rightarrow E_{2}\left(\mathrm{~K}_{2}\right)+\mathrm{P}_{\mathrm{i}} \rightarrow \ldots$. The enzyme will remain preferentially in state $E_{2}\left(\mathrm{~K}_{2}\right)$ due to the following rate-limiting step. $(B)$ In the case of the Ca-ATPase, the dye 2BITC was found to be an excellent detector of the electrochromic reaction steps. Starting with a buffer that contained sub-micromolar traces of $\mathrm{Ca}^{2+}$ ions, addition of $100 \mu \mathrm{M}$ EGTA chelated all $\mathrm{Ca}^{2+}$ ions and led to state $E_{1}$. Addition of $190 \mu \mathrm{M} \mathrm{CaCl}{ }_{2}$ induced the transition into the state $\mathrm{Ca}_{2} E_{1}$, addition of $1 \mathrm{~mm}$ ATP induced the transition preferentially into state $\mathrm{P}-E_{2}$ and $15 \mathrm{~mm} \mathrm{CaCl}{ }_{2}$ into state $\mathrm{P}-E_{2} \mathrm{Ca}_{2}$. This sequence of additions maintains successively the states $\mathrm{Ca}_{\mathrm{x}} \mathrm{E}_{1}, E_{1}(+E G T A)$, $\mathrm{Ca}_{2} E_{1}(+C a), \mathrm{P}-E_{2}(+A T P)$ and $\mathrm{P}-E_{2} \mathrm{Ca}_{2}(+C a)$.
Determination of Wavelengths for Maximal Response on Substrate-Induced PARTIAL REACTIONS

As has been shown previously with the styryl dye RH421, it is possible to maintain steady-state conditions of defined protein states by appropriate buffer conditions. In the case of the Na,K-ATPase a socalled standard experiment was introduced, which started in a buffer that initially contained $30 \mathrm{~mm}$ histidine, $1 \mathrm{~mm}$ EDTA, $5 \mathrm{~mm} \mathrm{MgCl}_{2}$, pH 7.2, $200 \mathrm{~nm}$ fluorescent dye and $8-9 \mu \mathrm{g} / \mathrm{ml}$ protein. The initial state of the ion pumps obtained under this condition was $E_{1}$. The experiment was performed by consecutive addition of substrates to stabilize subsequent steady states in the pump cycle: $+50 \mathrm{~mm} \mathrm{NaCl}$ to reach the state $\mathrm{Na}_{3} E_{1}$, $+0.5 \mathrm{~mm}$ ATP transfers the protein mainly into state $\mathrm{P}-E_{2}$, and $+20 \mathrm{~mm} \mathrm{KC1}$ maintains preferentially $E_{2}\left(\mathrm{~K}_{2}\right)$ (Stürmer et al., 1991). An example of such an experiment is shown in Fig. $2 A$. A correspondent standard experiment was also introduced for the SR Ca-ATPase (Butscher et al., 1999): in buffer initially containing $25 \mathrm{~mm}$ tricine, 50 $\mathrm{mm} \mathrm{KCl}, 1 \mathrm{~mm} \mathrm{MgCl}_{2}$, and approximately $500 \mathrm{~nm}$ $\mathrm{Ca}^{2+}$ (according to Fura-2 measurements), pH 7.2, $200 \mathrm{~nm}$ fluorescent dye and protein $(19 \mu \mathrm{g} / \mathrm{ml})$. The initial state of the ion pump in this buffer condition was not well defined due to the undefined $\mathrm{Ca}^{2+}$ concentration, therefore, we named it $\mathrm{Ca}_{\mathrm{x}} E_{1}$ with approximately $x \leq 1$. The state $E_{1}$ was induced by addition of $0.1 \mathrm{~mm}$ EGTA, and subsequently $\mathrm{Ca}_{2} E_{1}$ by adding $190 \mu \mathrm{M} \mathrm{CaCl}_{2}, \mathrm{P}-E_{2}$ by $1 \mathrm{mM}$ ATP and P$E_{2} \mathrm{Ca}_{2}$ by $15 \mathrm{~mm} \mathrm{CaCl}_{2}$ (Fig. $2 B$ ). 

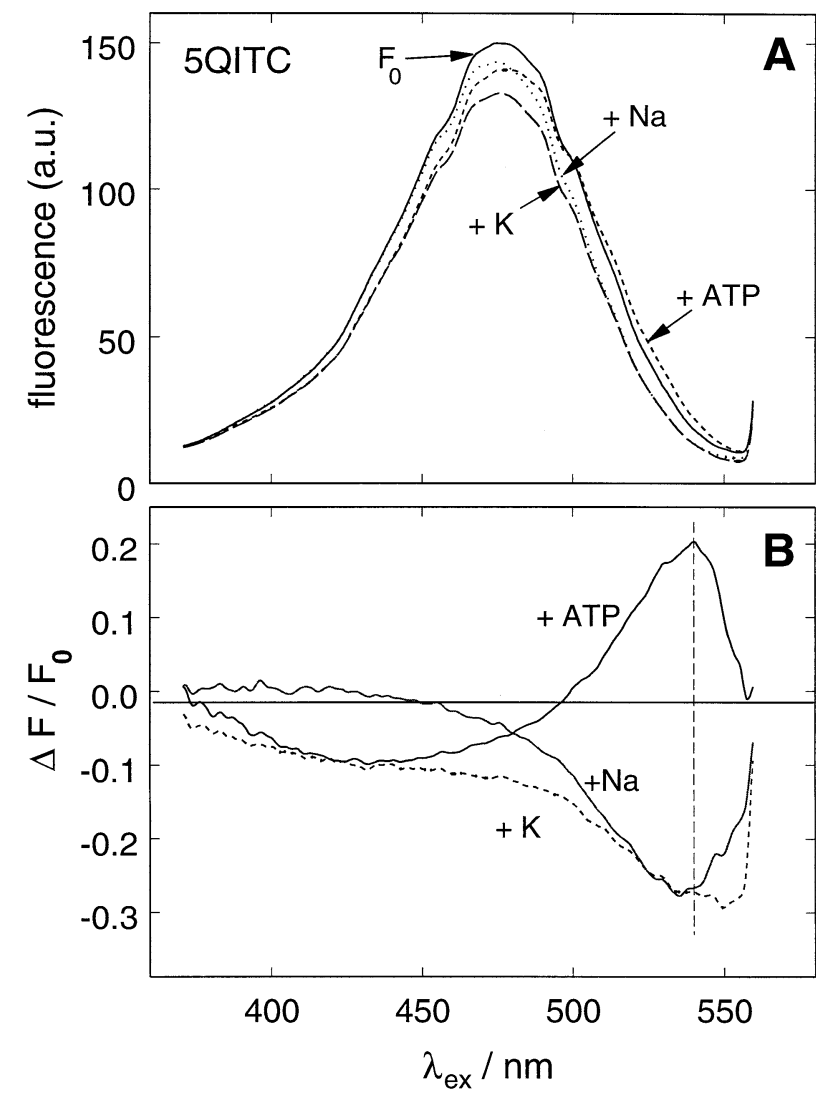

Fig. 3. Spectral dependence of the styryl dye 5QITC on different substrate conditions in membranes containing Na,K-ATPase. $(A)$ In the presence of $200 \mathrm{~nm} 5$ QITC and $9 \mu \mathrm{g} / \mathrm{ml} \mathrm{Na}, \mathrm{K}$-ATPase and in the absence of any monovalent cations in the buffer, the excitation spectrum was measured (solid line, marked $F_{0}$ ). The emission wavelength was set to $590 \mathrm{~nm}$. Subsequently $50 \mathrm{~mm} \mathrm{NaCl}(+N a)$, $1 \mathrm{~mm}$ ATP $(+A T P)$ and $20 \mathrm{~mm} \mathrm{KCl}(+K)$ were added (see Fig. 2) and the respective spectra taken. The wavelength of the absorption maximum was $470 \pm 5 \mathrm{~nm}$. $(B)$ The relative changes between the different spectra were calculated as $\Delta F / F_{0}=\left(F_{\text {+ substrate }}-F_{0}\right) / F_{0}$ and plotted against the wavelength. The most significant fluorescence changes were found at the red edge of the excitation spectrum, $\lambda_{\Delta \mathrm{Fmax}}=540 \pm 5 \mathrm{~nm}$ (dashed vertical line). The found maximum values of $\Delta F / F_{0}$ depend on the density of active $\mathrm{Na}, \mathrm{K}$ ATPase in the membranes and varied between experiments from different preparations.

At each steady-state condition of the standard experiments, emission spectra were taken for 19 of the styryl dyes introduced above. To increase the signal-to-noise ratio each spectrum was measured five times and the average calculated. An example is shown in Fig. $3 A$, in which 5QITC was applied in $\mathrm{Na}, \mathrm{K}-\mathrm{ATPase}$-containing membranes. The excitation range was between $400 \mathrm{~nm}$ and $570 \mathrm{~nm}$, the emission wavelength was kept constant at the emission maximum of $590 \mathrm{~nm}$. To determine the excitation wavelength for optimal fluorescence changes upon substrate additions, normalized difference spectra were calculated between each substrate condition and the initial spectrum, $F_{0}$, which was taken before the first substrate was added. The result is shown in Fig. $3 B$. From these experiments, for example, the optimum excitation wavelength of 5QITC was determined to be $542 \mathrm{~nm}$, and in the experiment shown, the fluorescence levels of the different substrate conditions relative to the initial level, $F_{0}$, were -0.26 for state $\mathrm{Na}_{3} E_{1}$, +0.2 for state P-E and -0.27 for a mixture of states $E_{2}\left(\mathrm{~K}_{2}\right)$ and $\left(\mathrm{Na}_{3}\right) E_{1}-P$. In Tables 3 and 4 the results are compiled, which were obtained as averages from a number of different enzyme preparations of $\mathrm{Na}, \mathrm{K}-\mathrm{ATPa}$ e or SR Ca-ATPase with all dyes investigated. Control experiments with lipid vesicles made of DOPC by the dialysis method were performed to determine the effect of the substrates of the $\mathrm{Na}, \mathrm{K}$-ATPase, i.e., $50 \mathrm{~mm} \mathrm{NaCl}, 0.5 \mathrm{~mm}$ ATP and $20 \mathrm{~mm} \mathrm{KCl}$, on the fluorescence of 5QITC when no ion pumps were present. An almost wavelengthindependent decrease of the fluorescence, $\Delta F / F_{0}$, was observed as $-2.5 \%\left(\mathrm{Na}^{+}\right),-6 \%$ (ATP) and $-9.3 \%$ $\left(\mathrm{K}^{+}\right)$, which can be discussed as the major source of the amplitude decrease of the absorption spectra visible in Fig. $3 A$.

\section{Effect of Dye Concentration}

To investigate the effect of dye concentration on the amplitude of the fluorescence responses, standard experiments as shown in Fig. 2 were performed with 5QITC and $\mathrm{Na}, \mathrm{K}$-ATPase-containing membranes, as well as with 2BITC and SR membranes in a dye concentration range between $50 \mathrm{~nm}$ and $600 \mathrm{~nm}$. The substrate-specific responses of both ion pumps, and, as derived quantity, the number of dye molecules per pump molecule, are shown as function of dye concentration in Fig. 4. To obtain maximum fluorescence responses at a minimum ratio of dye/pumps, for both protein preparations a concentration of $200 \mathrm{nM}$ was chosen for most of the experiments. With the known ratio of protein/lipid of $1: 1(\mathrm{w} / \mathrm{w})$ in the case of the Na,K-ATPase, about 175 lipid molecules per pump protein are estimated. In the presence of $200 \mathrm{~nm}$ dye, the lipid/dye ratio is 30 .

\section{Analysis of the Effect of the Length OF SPACER AND TAIL}

The dependence of the substrate-induced fluorescence responses on the spacer length, $s$, and on the length of the alkyl chain, $n$, of the tail is shown in Fig. 5 for SR membranes containing Ca-ATPase and in Fig. 6 for $\mathrm{Na}, \mathrm{K}$-ATPase-containing membrane fragments.

When the resulting effects of the different dyes on both enzyme preparations are compared, the first striking observation is that in the case of the Na, KATPase a significant dependence on spacer and tail length was found, while in the case of the SR CaATPase such a dependence could not be detected. From Fig. 5 it can be seen that variations of the re- 
Table 3. Comparison of spectroscopic data obtained with membranes containing Na,K-ATPase and of substrate-specific responses (pH 7.2)

\begin{tabular}{|c|c|c|c|c|c|c|}
\hline Dye & $\begin{array}{l}\text { Excitation } \\
\text { maximum } \\
\lambda / \mathrm{nm}\end{array}$ & $\begin{array}{l}\text { Emission } \\
\text { maximum } \\
\lambda / \mathrm{nm}\end{array}$ & $\begin{array}{l}\text { Optimal } \\
\text { detection at } \\
\lambda_{\mathrm{ex}} / \mathrm{nm}\end{array}$ & $\Delta F_{\mathrm{Na}} / F_{0}$ & $\Delta F_{\mathrm{ATP}} / F_{0}$ & $\Delta F_{\mathrm{K}} / F_{0}$ \\
\hline 1PITC & 488 & 578 & $0^{\mathrm{a}}$ & $0^{\mathrm{a}}$ & $0^{\mathrm{a}}$ & $0^{\mathrm{a}}$ \\
\hline 2PITC & 487 & 590 & 540.0 & 0.02 & 0.061 & 0.018 \\
\hline 3PITC & 483 & 583 & 542.0 & -0.026 & 0.121 & 0.023 \\
\hline 5PITC & 470 & 590 & 542.0 & -0.135 & 0.132 & -0.095 \\
\hline 2BITC & 485 & 575 & 541.0 & 0.07 & 0.014 & -0.037 \\
\hline 3BITC & 486 & 585 & 552.0 & 0 & 0.055 & -0.01 \\
\hline 4BITC & 481 & 590 & 525.0 & -0.02 & 0.083 & 0.023 \\
\hline 5BITC & 475 & 595 & 541.0 & -0.092 & 0.129 & -0.091 \\
\hline 7BITC & 482 & 587 & 541.5 & 0.041 & 0.414 & 0.139 \\
\hline 1QITC & 465 & 600 & 538.5 & -0.067 & 0.069 & -0.047 \\
\hline 2QITC & 470 & 595 & 539.5 & -0.061 & 0.111 & -0.087 \\
\hline 3QITC & 474 & 590 & 540.0 & -0.065 & 0.108 & -0.089 \\
\hline 4QITC & 470 & 595 & 542.5 & -0.153 & 0.123 & -0.141 \\
\hline 5QITC & 470 & 590 & 542.5 & -0.280 & 0.249 & -0.270 \\
\hline 6QITC & 470 & 585 & 540.5 & -0.269 & 0.085 & -0.228 \\
\hline 7QITC & 473 & 582 & 543.0 & -0.126 & 0.116 & -0.100 \\
\hline 2HITC & 475 & 590 & a & $0^{\mathrm{a}}$ & $0^{\mathrm{a}}$ & $0^{\mathrm{a}}$ \\
\hline 5HITC & 470 & 595 & 540.0 & -0.138 & 0.108 & -0.180 \\
\hline 6HITC & 495 & 570 & 531.5 & -0.130 & 0.129 & -0.185 \\
\hline
\end{tabular}

a 1 PITC and 2 HITC did not produce significant responses on substrate addition.

Table 4. Comparison of spectroscopic data obtained with SR membranes containing Ca-ATPase and of substrate specific responses (pH 7.2)

\begin{tabular}{|c|c|c|c|c|c|c|}
\hline Dye & $\begin{array}{l}\text { Excitation } \\
\text { maximum } \\
\lambda / \mathrm{nm}\end{array}$ & $\begin{array}{l}\text { Emission } \\
\text { maximum } \\
\lambda / \mathrm{nm}\end{array}$ & $\begin{array}{l}\text { Optimal } \\
\text { detection at } \\
\lambda_{\text {exc }} / \mathrm{nm}\end{array}$ & $\Delta F_{\mathrm{EGTA}} / F_{0}$ & $\Delta F_{\mathrm{Ca}} / F_{0}$ & $\Delta F_{\mathrm{ATP}} / F_{0}$ \\
\hline 2PITC & 481 & 590 & 525.0 & 0.505 & 0.002 & -0.093 \\
\hline 5PITC & 483 & 576 & 546.5 & 0.422 & 0.098 & 0.121 \\
\hline 2BITC & 482 & 590 & 540.0 & 0.529 & 0.068 & 0.018 \\
\hline 5BITC & 483 & 584 & 546.0 & 0.344 & 0.008 & 0.025 \\
\hline 7BITC & 483 & 574 & 548.5 & 0.417 & 0.019 & 0.005 \\
\hline 1QITC & 470 & 585 & 537.5 & 0.420 & 0.129 & 0.137 \\
\hline 2QITC & 482 & 590 & 530.0 & 0.466 & 0.022 & -0.022 \\
\hline 3QITC & 482 & 580 & 544.5 & 0.415 & 0.075 & 0.094 \\
\hline 4QITC & 482 & 583 & 543.0 & 0.476 & 0.084 & 0.022 \\
\hline 5QITC & 482 & 582 & 546.0 & 0.419 & 0.007 & 0.018 \\
\hline 6QITC & 482 & 570 & 540.0 & 0.382 & 0.06 & 0.093 \\
\hline 7QITC & 482 & 574 & 540.0 & 0.472 & 0.033 & 0.055 \\
\hline 2HITC & 481 & 590 & 530.0 & 0.518 & -0.010 & -0.038 \\
\hline 5HITC & 482 & 583 & 540.0 & 0.392 & 0.05 & 0.063 \\
\hline
\end{tabular}

lative fluorescence level of state $E_{1}$ of the SR CaATPase, which is maintained by addition of EGTA, are not significant with respect to the length of tail $n$ or spacer $s$. The error bars of the data in traces $b$ (state $\left.\mathrm{Ca}_{2} E_{1}\right)$ and $c\left(\mathrm{P}-E_{2}\right)$ were removed for sake of clarity; they were of the same magnitude as those shown for trace $a$. There is a minor difference of the average of $\Delta F / F_{0}$ of state $E_{1}$ (trace $a$ ) between the 2XITC dyes $(0.40 \pm 0.02)$ and the 5 XITC dyes $(0.51$ $\pm 0.01)$. When regression lines were fitted through the $\Delta F / F_{0}$ levels of the $\mathrm{Ca}_{2} E_{1}$ and $\mathrm{P}-E_{2}$ states, small slopes were obtained (not shown), however, there is no clear tendency, and horizontal lines with the am- plitude of the average values were within the range of the error bars (traces $b$ and $c$ ). From a comparison of all investigated dyes we gave 2BITC the preference for experiments with SR Ca-ATPase.

In contrast to the findings with SR membranes containing Ca-ATPase, a clear dependence on tail or spacer length was found in the case of Na,K-ATPasecontaining membrane preparations (Fig. 6). In Fig. $6 A$ a pronounced response of $\Delta F / F_{0}$ was observed in the range of $n=4-6$. It is more obvious for the states $\mathrm{Na}_{3} E_{1}$ (trace $a$ ) and $E_{2}\left(\mathrm{~K}_{2}\right)$ (trace $c$ ) than for the state $\mathrm{P}-E_{2}($ trace $b)$, where only 5 QITC showed a $\Delta F / F_{0}$ greater than 0.2 . When for the optimal tail length, 

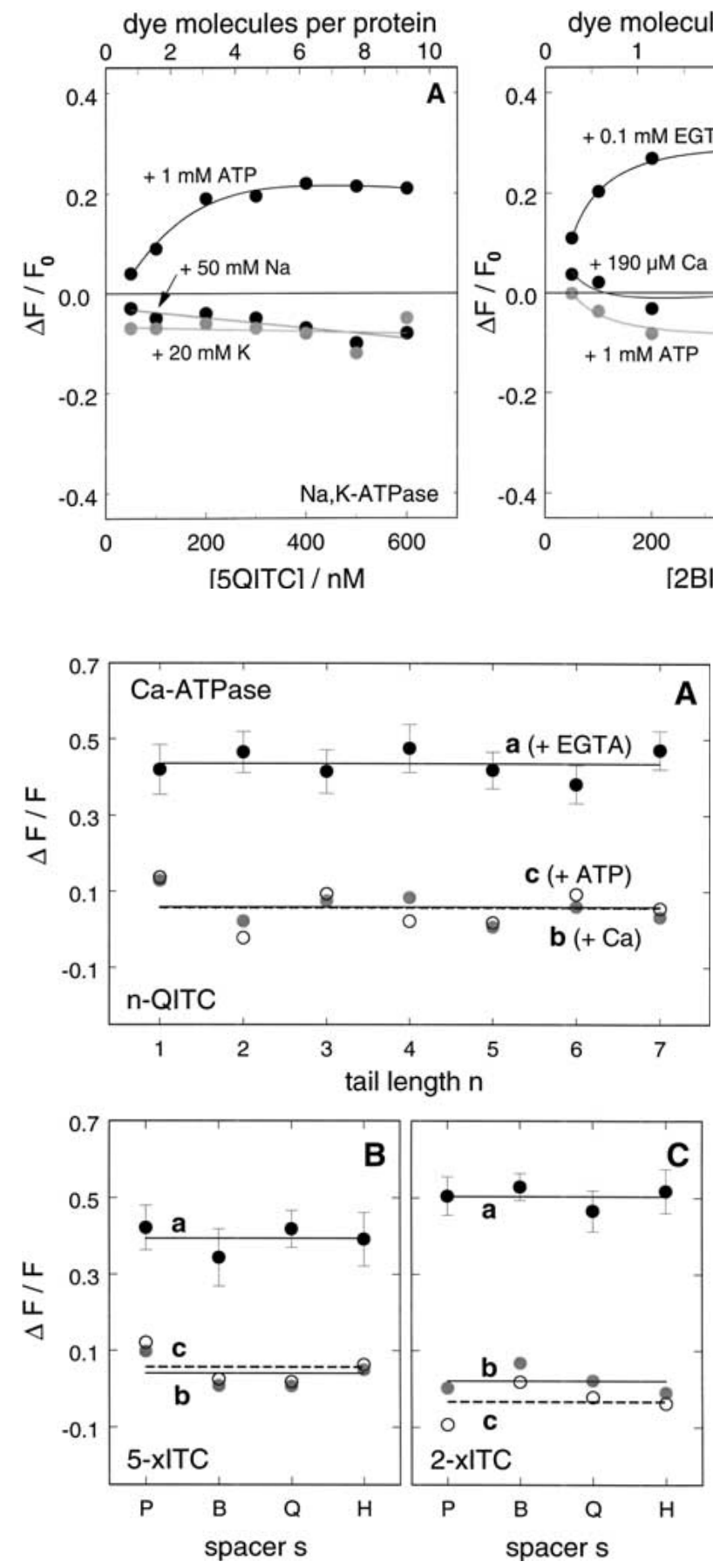

Fig. 5. Dependence of Ca-ATPase-specific fluorescence changes, $\Delta F / F_{0}$, on tail length, $n$, and spacer length, $s$, of the $n$ XITC dyes. (A) With a spacer length of $5 \mathrm{CH}_{2}$ groups (QITC) the responses on addition of $0.1 \mathrm{~mm} \operatorname{EGTA}(a), 190 \mu \mathrm{M} \mathrm{CaCl}_{2}(b)$ and $1 \mathrm{~mm} \operatorname{ATP}(c)$ are plotted against the number of carbon atoms in the alkyl chain. Results of the variations in the length of the spacer, $s$, are shown for $n=5(B)$ and for $n=2(C)$. Lines through the data represent the average value of the corresponding data set. The error bars for the data in traces $b$ and $c$ were removed for sake of clarity; they are of the same size as those shown for the data of trace $a$.

$n=5$, the spacer $s$ is varied (Fig. 6B), again only 5QITC showed significantly increased fluorescence changes. Variation of $s$ in dyes with a tail $n=2$ revealed that these dyes could not detect the Na,KATPase-specific fluorescence by significantly large fluorescence changes (Fig. 6C). Comparison of all tested $n$ XITC dyes showed that 5QITC is the most appropriate dye with which to investigate electrogenic partial reactions of the Na,K-ATPase.

When 5QITC was compared with the well established styryl dye RH421, it turned out they are comparable, although the response on the ATP-induced partial reaction, $\mathrm{Na}_{3} E_{1} \rightarrow \ldots \rightarrow \mathrm{P}-E_{2}$, is more pronounced in the case of RH421 (Table 5). In contrast to RH421, with which the states $\mathrm{Na}_{3} E_{1}$ and $E_{2}\left(\mathrm{~K}_{2}\right)$ had different fluorescence intensities, in the case of 5QITC, both states had the same levels. However, most of the apparent fluorescence decrease in state $E_{2}\left(\mathrm{~K}_{2}\right)$ has to be accounted to the unspecific effect observed also in pure lipid vesicles (see above). In the case of the SR Ca-ATPase only minor differences of $\Delta F / F_{0}$ between the different $n$ XITC dyes were found, however, RH421 has been shown to produce no significant changes for any of the electrogenic partial reactions of the Ca-ATPase (Butscher et al., 1999).

\section{Estimation of the Position of the Styryl Chromophores in the Lipid Phase of the Membrane}

The observed dependence of $\Delta F / F_{0}$ of the different $\mathrm{Na}, \mathrm{K}$-ATPase states on the $n$ XITC dyes led to the idea to determine the position of the chromophore vertical to the surface of the membrane. A tool available to get information on the vertical position was the use of doxyl-labeled lipids with defined position of the quenching group in the lipid bilayer. Doxyl labels attached to lipid molecules may be used as effective quenchers of the fluorescence of membrane-bound (styryl) dyes (Chattopadhyay \& Lon- 

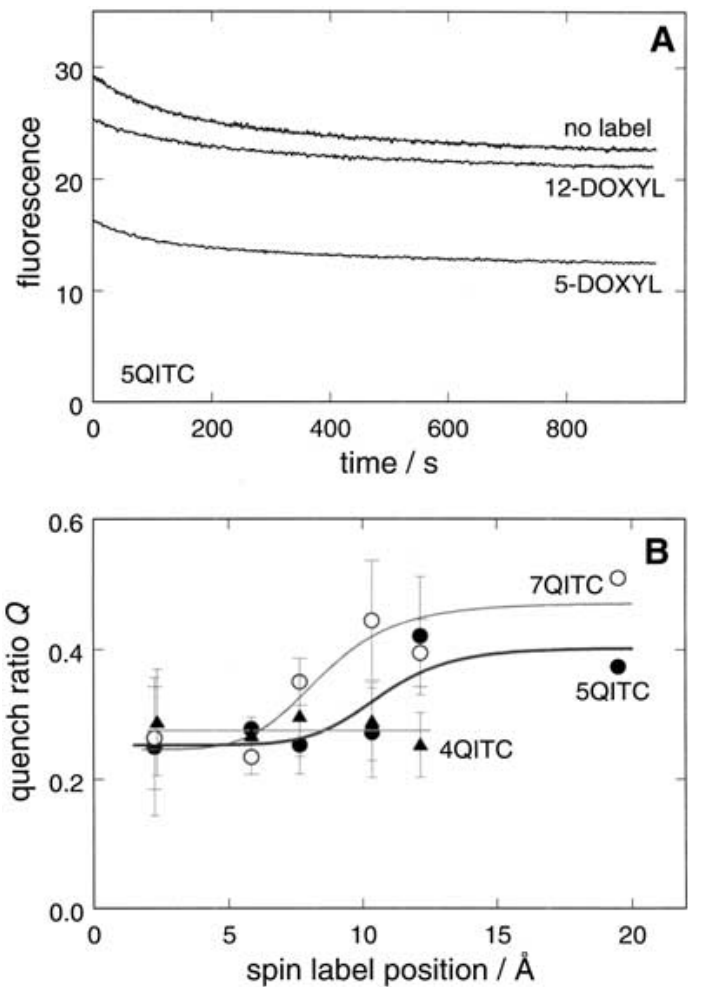

Fig. 8. Quenching of $n$ XITC dyes by doxyl labels attached to various carbons of the fatty acid chains. $(A)$ Time course of the fluorescence intensity when freshly prepared vesicles consisting of 5QITC/doxyl lipid/DOPC (1:45:255) were filled into a cuvette. The unquenched fluorescence is compared with preparations containing 12-doxyl-and 5-doxy-labeled lipid. The steady-state level was determined using a fit function that reproduced the initial effects by two decaying exponential functions (fitting line through the "no label" data). (B) The quench effect of the different doxyl labels on three $n$ QITC dyes. The quench ratio $Q$ (see text) was plotted against the position where the quencher is proposed to be situated in the membrane (Fig. 7). The lines were drawn to visualize the position dependence of quench effects in the case of 4QITC (triangles), 5QITC (filled circles) and 7QITC (open circles). The error bars represent the standard deviation of experiments performed under identical conditions.

be fitted perfectly with the function given in Methods as exemplified for the uppermost fluorescence trace in Fig. $8 \mathrm{~A}$. For each of the investigated dyes the steadystate fluorescence obtained in the presence of one of the five quenching doxyl labels (or TEMPO PC) was compared to the fluorescence level in the absence of a quencher by calculating the quench ratio, $Q=$ $F_{\text {+quencher }} / F_{\text {-quencher }}$. Part of the results are shown in Fig. $8 B$, where $Q$ is plotted against the position of the doxyl label within the lipid bilayer for three of the dyes. The positions were calculated according to a published estimate (Sassaroli et al., 1995).

It was found that in the case of short alkyl chains, $n<4$, the quench ratio, $Q$, was not significantly dependent on the position of the quencher and, therefore, an average value of $Q$ could be calculated. A tendency that quenching is stronger when
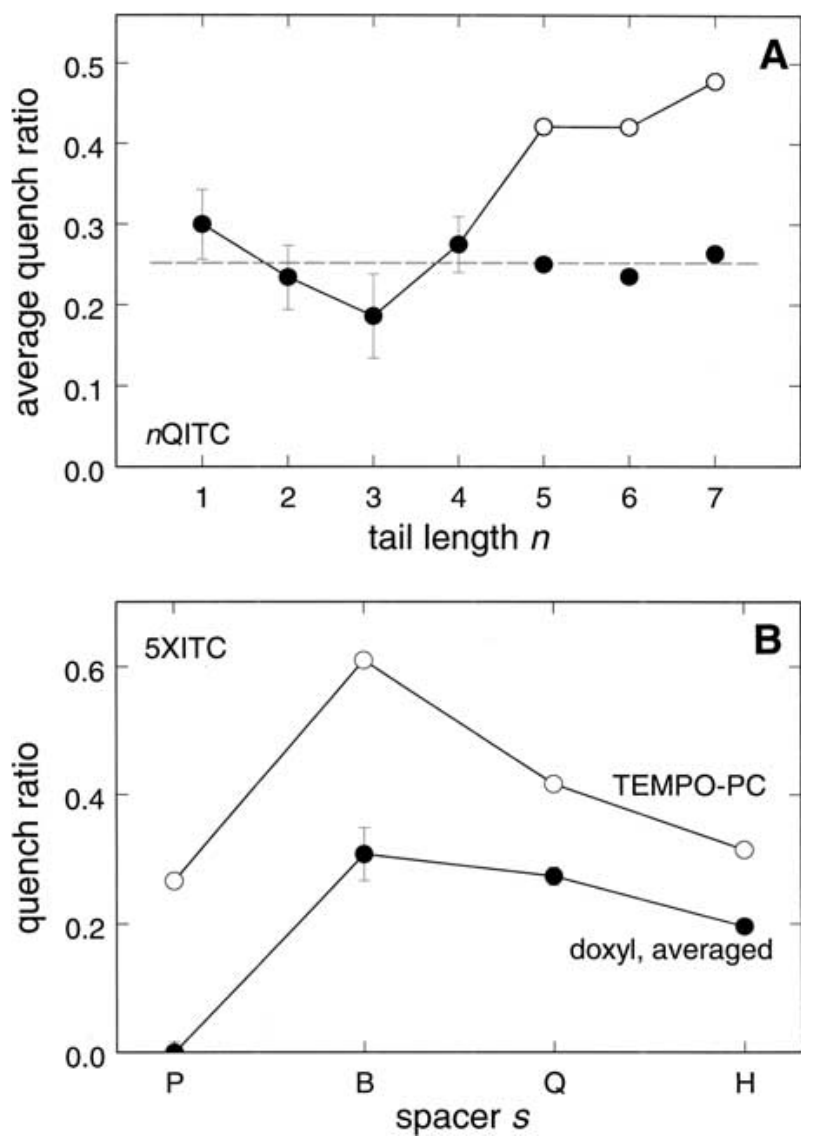

Fig. 9. Average quench ratio, $Q_{\mathrm{Av}}$, of different $n \mathrm{XITC}$ dyes. $(A)$ Solid circles represent the dependence of $Q_{\mathrm{AV}}$ on tail length for $n=$ 1 to 4 . The error bars are standard deviations calculated from the experiments with all doxyl labels and with TEMPO PC (if measured). In the case of $n \geq 4$ a significant dependence of the spin label position was observed. The solid circles represent the quench ratio obtained from the inner quenchers, the open circles that of quenchers close to the membrane surface (see Fig. 8). (B) Dependence on spacer length of the 5XITC dyes. The solid circles represent the averaged quench ratio of the experiments with doxyl labels, the open circles are from measurements with TEMPO PC. In the case of 5PITC, only TEMPO PC produced a significant quench effect.

the position of the doxyl label is closer to the surface of the membrane, was found in the case of the dyes with the longer alkyl chains, 5QITC to 7QITC (Fig. $8 B$ ). The large error bars of most of the data points reflect the poor reproducibility of this type of experiments. In consequence, we determined an average quench ratio, $Q_{\mathrm{Av}}$, obtained from all 5 doxyl labels (and from TEMPO-PC, if measured) in the case of 1 QITC to 4 QITC. In the case of 5QITC to 7QITC we made a distinction between the $Q$ of the inner and of the outer quenchers. The results are shown in Fig. $9 A$. It is obvious that the effect of spacer, $s$, had a greater impact on the quench ratio, $Q_{\mathrm{Av}}$, than the length, $n$, of the alkyl chains of the tail (Fig. 9B). The dyes with the shortest spacer, $s=3$ ( $n$ PITC), were hardly affected by the intra-membrane quenchers $\left(Q_{\mathrm{AV}}=0.0\right.$ 
$\pm 0.016)$. Only in vesicles with TEMPO-PC, which has the quenching label attached to the polar head group, a quench ratio $Q=0.26 \pm 0.02$ was detected. That was interpreted as indication that the dye with the shortest spacer probably did not insert into the hydrophobic core of the membrane but remained with the sensitive part of its chromophore close to the polar head groups where the TEMPO label is located. BITC and QITC dyes ( $s=4$ and 5, respectively) were quenched by about $28 \pm 2 \%$ by the doxyl labels and $50 \pm 10 \%$ by TEMPO-PC. An even longer spacer, HITC $(s=6)$, again, had a smaller quench ratio (Fig. $9 B)$.

These findings are in agreement with the concept that the depth of the styryl chromophore is shifted within the lipid membrane and that this is a function of the spacer length. The dependence of $Q$ as function of the hydrophobic tails was less pronounced (Fig. $9 A$ ). Most of the averaged $Q$ values for different tail length, $n$, did not significantly deviate from the overall average determined from all QITC dyes of $0.249 \pm$ 0.014 . Only the dye 3QITC was less strongly quenched when compared with the average $(0.186 \pm 0.052)$. As shown in Fig. $8 B$, in the case of 5QITC and 7QITC, and also in 6QITC (not shown), the quench ratio, $Q$, was in the order of 0.25 for spin labels with a position deeper inside the membrane $(x \leq 10 \AA)$, which is about the average quench ratio (Fig. $9 A$ ), but it was significantly larger for $x>10 \AA(Q \approx 0.4-0.5)$.

\section{Discussion}

Position of the Chromophore of the $n \mathrm{XITC}$ DYE

In the literature, the fluorescence responses of various styryl dyes on the same reaction steps of the $\mathrm{Na}, \mathrm{K}$ ATPase gave a lot of discussion on the detection mechanism of these probes. Especially the contribution of the effect of a specific interaction of dye molecule with changing protein conformations $(\mathrm{Fe}-$ dosova et al., 1995) or the electrochromic effect of a position-dependent sensitivity for charge movements (Bühler et al., 1991) were discussed as origin of the fluorescence changes. When originally tested in nerve membranes, typical fluorescence responses, $\Delta F / F_{0}$, of styryl dyes on changes of the transmembrane voltage were about 14 to $20 \%$ per $100 \mathrm{mV}$ (Grinvald et al., 1987). In the case of open membrane fragments containing $\mathrm{Na}, \mathrm{K}$-ATPase (where both sides of the membrane are short-circuited and no transmembrane potential is possible) certain partial reactions are accompanied by relative fluorescence changes with amplitudes in the order of $100 \%$ (Klodos \& Forbush, H., 1988, Bühler et al., 1991).

Now a more systematic analysis is possible with a family of styryl dyes, called $n$ XITC, which have the same chromophore but in which the length of the spacer, $s$, between the chromophore and the polar (but uncharged) head group and the length of the two (identical) hydrophobic tails is systematically varied.

In the case of the Na,K-ATPase, a dependence on spacer and tail length of the $n$ XITC dyes was found: the addition of a single $\mathrm{CH}_{2}$-group to spacer or tail could already produce significant differences in the substrate-dependent fluorescence changes (Fig. 6). Therefore, it was important to study properties of these dyes systematically to gain information on the origin of the observed behavior and how these effects depended on the chromophore position vertically to the plane of the membrane in the lipid bilayer.

Systematic and quantitative experiments on the position dependence had to be performed with artificial lipid vesicles, which allowed the precise control of concentrations of lipid, dye and quenching agents that was necessary to compare different experiments. This technique was applied successfully before (Chattopadhyay \& London, 1987, Kachel et al., 1998, Kaiser \& London, 1998).

A method introduced by Chattopadhyay and London (1987) allows the determination of several parameters concerning the distances between a chromophoric group within the lipid phase and quencher molecules attached to the acyl chain of lipids. One parameter is the critical radius, $R_{\mathrm{C}}$, which defines the sphere around the spin label within which quenching occurs. From the experiments performed in the framework of this paper, an average value of $R_{\mathrm{C}}=5.56 \pm 0.87 \AA$ could be determined for the interaction of doxyl quenchers and $n X I T C$ dyes. This number has to be compared with the size of the chromophore (Fig. 7) and it provides an idea on the spatial resolution which has to be taken into account when the position of the $n$ XITC chromophore will be discussed.

Assuming that in the excited state of the chromophore a delocalized electron is shifted from the inner aniline unit of the chromophore to the pyridine unit closer to the membrane surface (Fischer, 1974), then the quench effect of the excited state is to be expected preferentially in proximity to the pyridine unit of the chromophore. (Charge shifts up to $3 \mathrm{~nm}$ were reported between ground and excited state of styryl dyes (Fromherz \& Lambacher, 1991).) From the results shown in Fig. 8 and 9 it can be seen that the doxyl-labeled lipids are able to quench all scrutinized $n$ XITC dyes (with exception of 5PITC) in pure lipid vesicles, with an average quench ratio of about 0.25 when the ratio labeled lipid to total lipid was 0.15 . The maximum quench effect in the order of 0.4 to 0.5 was observed with the doxyl labels, which were positioned more closely to the membrane surface (Fig. 8), and with TEMPO PC, which has the quenching label in the region of the polar lipid head 
group. TEMPO PC had always a significantly stronger effect than the quenchers attached to the acyl chain of the lipid (Fig. 9). Obviously, the position dependence of the quench effect was too unspecific to be able to pin down a defined position of the chromophore in the $n$ XITC dyes tested. However, from Fig. $8 B$ and $9 A$ it can be seen that in the series of $n$ QITC dyes all members with a tail of $n \leq 4$ were affected in the same way by each of 5 doxyl quenchers, while in the case of $n \geq 5$, an increase of the quench ratio, $Q$, could be observed when the doxyl labels had a position further than $10 \AA$ away from the middle of the membrane, and in the case of $n=7$, an increase of $Q$ was observed at about $7.5 \AA$.

The absence of any position dependence of the quench effect in the case of $n$ XITC dyes with hydrophobic tails shorter than 5 carbon atoms $(n \leq 4)$ may be explained by either a broad distribution of the dye molecules perpendicular to the membrane plane within the hydrophobic core of the membrane, so that all doxyl labels had an equal share of chromophores within the critical radius, $R_{\mathrm{C}}$, or, more probable, by the fact that the aniline unit of the dye was placed, independent of the respective dye, at a distance of about $10 \AA$ from the center of the membrane, so that the delocalized excited electron was within $R_{\mathrm{C}}$ of all doxyl labels. When the alkyl chains of the dyes become longer, then they may preferentially not inter-digitate with the acyl chains of the opposite lipid leaflet, but push the chromophore towards the membrane surface and increase the quench effect, $Q$, of the doxyl labels at the positions $x \geq 10 \AA$ from the middle of the membrane. These assumptions would explain the observed dependence of the quench ratio, $Q$, on the tail length of the $n \mathrm{XITC}$ dyes.

The effect of the spacer, $s$, on $Q$ is shown in Fig. $9 B$. Eye-catching is the difference of the efficacy to quench between TEMPO-PC and the doxyl labels, which was almost a factor of 2 . This indicates that the electron in the excited state of the dyes has to be closer to the lipid head groups, where the TEMPO label is attached, than to the acyl chains, which carry the doxyl labels. A special situation was found in the case of the 5PITC dye, which was quenched only by the TEMPO label and not significantly by any of the doxyl labels. A possible explanation for this observation would be that the dye did not insert properly into the hydrophobic matrix of the pure DOPC lipid bilayer. In the case of $\mathrm{Na}, \mathrm{K}$-ATPase-containing membranes with numerous different lipids, the series of $n$ PITC dyes showed small or no significant response on the electrogenic partial reactions (Table 3 ), while in contrast in the SR membrane vesicles with the Ca-ATPase, significant fluorescence changes could be detected (Table 4). So far no explanation can be provided for these observations.

On the basis of the presented experimental results, the spatial resolution of the position of the chromophore is very poor and, unfortunately, the different members of the $n$ XITC dye family may not be used to probe the strength of local electric fields at defined positions within lipid bilayers (or proteincontaining membranes). However, in the case of the $n$ QITC series, it was found that 5 QITC to 7 QITC were significantly more strongly affected by quenchers located in the range between $10 \mathrm{~nm}$ and the surface of the membrane (Figs. 8 and 9), a finding which is in agreement with the concept that the pyridine unit is positioned between $10 \mathrm{~nm}$ and $15 \mathrm{~nm}$ from the center of the bilayer.

\section{Detection Mechanism of the Styryl Dyes}

To discuss the question of the mechanism of major contribution to fluorescence changes induced by partial reactions of the P-type ion pumps, a number of observations shall be compiled that are supporting a preferentially electrochromic detection mechanism of styryl dyes, such as RH421 and the nXITC: (1) It is known that fluorescence changes, as they are observed by partial reactions of the Na,K-ATPase pump cycle, can be induced by incorporation of hydrophobic ions, such as $\mathrm{TPB}^{-}$and $\mathrm{TPP}^{+}$, and the increase or decrease of the fluorescence intensity is always and in the same way correlated with the sign of the charges (Bühler et al., 1991). This was also found in the case of the $n$ XITC dyes. (2) In Fig. 4 the concentration dependence of the fluorescence signals shows that an increase of the dye concentration from $200 \mathrm{~nm}$ to $600 \mathrm{~nm}$ did not significantly alter the fluorescence change, $\Delta F / F_{0}$, of the investigated reaction steps of the ion pumps. This concentration independence may be better explained by effects of local electric fields than by a (specific) interaction of dye molecules with altering protein conformations. In the latter case, 9 dye molecules would have to interact with the protein in the same way as 3 molecules do (Fig. 4A). If a considerable fraction of dye molecules would not participate in the detection process of the protein conformation, then $\Delta F / F_{0}$ would have to decrease in a hyperbolic concentration dependence when the "interaction sites" of the protein are occupied by dye molecules. If, in contrast, the dye molecules are diffusing through the lipid phase of the membrane, an increase of the dye concentration would hardly affect the amplitude of $\Delta F / F_{0}$ because the (average) electric field in the membrane is not significantly altered when the ratio of 60 lipids per dye molecule is decreased to 20. (3) All significant fluorescence changes cohere with partial reactions of the ion pumps in which net charges are imported into or released from the protein (Stürmer et al., 1991; Stürmer \& Apell, 1992; Heyse et al., 1994; Bühler \& Apell, 1995; Domaszewicz \& Apell, 1999; Schneeberger \& Apell, 1999). On the other hand, it was shown that partial reactions, which contain con- 
formational transitions but no change of the number of ions inside the protein, did not affect the fluorescence emission, such as $E_{1}+2 \mathrm{~K}^{+} \rightarrow E_{2}\left(\mathrm{~K}_{2}\right)$ (Stürmer et al., 1991; Bühler \& Apell, 1995; Schneeberger $\&$ Apell, 2001) or $\mathrm{Na}_{3} E_{1} \rightarrow \mathrm{P}-E_{2} \mathrm{Na}_{3}$, which can be observed in high $\mathrm{Na}^{+}$concentrations (Stürmer \& Apell, 1992; Heyse et al., 1994). In the case of 2BITC and 2HITC, conformational transitions of the SR Ca-ATPase were also not accompanied by significant fluorescence changes (Butscher et al., 1999, Peinelt \& Apell, 2002). (4) The comparison of direct electric measurements and fluorescence experiments with RH421 demonstrated that the $\mathrm{Na}^{+}$-induced effects on the cytoplasmic side of the $\mathrm{Na}, \mathrm{K}$-ATPase coincide perfectly (Domaszewicz \& Apell, 1999). I.e., RH421 detects accurately the electrogenic binding and release of $\mathrm{Na}^{+}$. Therefore, we think that it is justified to analyze and interpret the results of the experiments on pump functions in this paper on the basis of ion movements detected by the electric field sensitivity of the $n$ XITC dyes.

\section{Detection of Pump Function by $n$ XITC}

A number of dyes of the $n$ XITC dye family could be used in a corresponding fashion to RH421 to detect substrate-induced partial reactions of the Na,K-ATPase (Table 3). The so-called standard experiments (Fig. 2) had basically the same appearance for RH421 and the $n$ XITC dyes, only the amplitudes varied as function of header and tail length (Table 3, Fig. 6). With respect to the specific fluorescence changes, $\Delta F /$ $F_{0}$, the dye optimal for Na,K-ATPase experiments, 5QITC, behaved comparable to RH421 (Table 5). In the case of the SR Ca-ATPase, the well established RH421 did not produce significant fluorescence changes (Butscher et al., 1999) but most of the $n$ XITC did (Table 4, Fig. 5).

When the spectral dependence of the 5QITC fluorescence on states of the pump cycle was investigated (Fig. 3), not only a red or blue shift according the electrochromic effect was found, but in addition, changes in the fluorescence yield. When the spectra were normalized to the same fluorescence maximum, it could be seen that distinct shifts of the absorption spectra exist between $F_{0}$ and $F(+\mathrm{Na})$ and $F(+\mathrm{ATP})$; however, the shift between $F_{0}$ and $F(+\mathrm{K})$ is very small $(<1 \mathrm{~nm}$, not shown). Control experiments with lipid vesicles without protein revealed that addition of $\mathrm{Na}^{+}$, ATP and $\mathrm{K}^{+}$produced a reduction of the fluorescence yield of 5QITC over the whole absorption spectrum with similar reductions at the maximum as they were observed with the Na,KATPase-containing membrane fragments, however, without a shift of the maximum wavelength (not shown). A possible explanation for the observed fluorescence decrease may be that the smaller chromophore of the $n$ XITC dyes (when compared with that of RH421) is closer to the membrane surface, and therefore more strongly affected by the addition of ionic substrates to the buffer. The pronounced effect of $\mathrm{K}^{+}$may be caused by the fact that the membrane is tenfold more permeable to $\mathrm{K}^{+}$than to $\mathrm{Na}^{+}$ions, which is mainly an effect of a higher partition coefficient of $\mathrm{K}^{+}$, and that $\mathrm{K}^{+}$ions might preferentially accumulate in the superficial part of the membrane.

In the case of the Ca-ATPase, none of the $n$ XITC dyes investigated showed a significant dependence on spacer or tail length for any of the tested partial reactions of the ion pump (Fig. 5). As has been shown recently (Butscher et al., 1999), ion-binding steps on both sides of the membrane produced large fluorescence changes (Fig. 2B), while the conformational transition, $\mathrm{Ca}_{2} E_{1} \rightarrow \mathrm{P}-E_{2}$ was accompanied only by minor fluorescence changes below $10 \%$ (depending on buffer $\mathrm{pH}$ ). The observed absence of any significant dependence of the fluorescence responses on dye structure may be explained on the basis of the publication of a crystal structure of SR Ca-ATPase with a resolution of $2.6 \AA$ (Toyoshima et al., 2000). According to the structural details that became available by this analysis, the $2 \mathrm{Ca}^{2+}$ ions are located side by side, with a distance of $5.7 \AA$, right in the middle of the transmembrane section of the protein. Under such a condition the potential-sensitive chromophores of all $n$ XITC dyes are placed between the aqueous phase and the position of the charges in the ion pump that produce the (symmetric) electric potential within the membrane dielectric. If the dielectric constant of the hydrophobic membrane interior is not very inhomogeneous, then the chromophores of all nXITC dyes will detect approximately the same strength of the electric field and, in consequence, report the same fluorescence changes when ions are bound or released, as it was observed in the experiments presented (Fig. 5).

In the case of the $\mathrm{Na}$, K-ATPase, an explicit dependence on tail and spacer length of the $n$ XITC dyes was found (Fig. 6). The maximum fluorescence changes of substrate-specific responses were detected with 5QITC. The addition or removal of one $\mathrm{CH}_{2}$ group from the spacer between the polar head group and the chromophore reduced the fluorescence responses by more than a factor of 2 (Fig. 6B). A similarly pronounced dependence on the number of $\mathrm{CH}_{2}$ groups was found for the ATP-dependent partial reaction when the tail length of the QITC dyes was altered (trace $b$ in Fig. 6A). In contrast, the ion binding and release reactions were affected in a broader range of tail lengths (traces $a, c$ in Fig. 6A). On the basis of the interpretation of position-dependent quench of the $n$ QITC (Figs. 8 and 9) it can be concluded qualitatively that the position of the electric field-producing charges have to be placed differently within the $\mathrm{Na}, \mathrm{K}$-ATPase in the states $\mathrm{Na}_{3} E_{1}$, 
P- $E_{2}$ and $E_{2}\left(\mathrm{~K}_{2}\right)$, which were characterized by the fluorescence levels plotted in Fig. 6. Unfortunately, so far no structural details of ion-binding sites of the $\mathrm{Na}, \mathrm{K}-\mathrm{ATP}$ ase are available with a spatial resolution comparable to that of the Ca-ATPase. However, in a recent publication it has been shown that both, direct electric measurements and fluorescence experiments with the styryl dye RH421, prove that binding of the third $\mathrm{Na}^{+}$ion on the cytoplasmic side, $\mathrm{Na}_{2} E_{1} \rightarrow$ $\mathrm{Na}_{3} E_{1}$, is an electrogenic process, and that the location of the bound $\mathrm{Na}^{+}$is $22-25 \%$ within the membrane dielectric (Domaszewicz \& Apell, 1999). This number refers to a dielectric distance, which may differ from the spatial distance (dependent on constancy or variation of the dielectric coefficient of the membrane interior). The quench ratios, $Q$, in the series of 5QITC to 7QITC showed the greatest changes between the spin labels placed at a distance of below $7 \AA$ and beyond $10 \AA$ from the center of the membrane (Fig. $8 B$ ). Therefore, the proposal is suggestive to place the outer pyridine unit, which carries the delocalized electron in the excited state of the dye, in the range between $7 \AA$ from the center of the membrane and its outside. To obtain a maximum fluorescence response on $\mathrm{Na}^{+}$binding, as in the case of 5QITC and 6QITC, the corresponding binding site for the 'electrogenic' $\mathrm{Na}^{+}$ion would be expected at a position between the aniline and pyridine unit, since then the bound $\mathrm{Na}^{+}$would introduce the maximum change of the local electric field for the electron when it moves into the excited state of the chromophore. On the basis of such a speculation, the location of the $\mathrm{Na}^{+}$binding site has to be situated at a topographic depth of $\sim 20 \%$ from the membrane surface (Fig. 7), a distance which is in a fair agreement with the dielectric determination.

\section{Structure-Function Relations Deduced from THE EXPERIMENTAL ObSERVATIONS}

Even if the determination of the position of the $\mathrm{Na}^{+}$ binding site at the moment has a number of speculative components, the striking difference between the SR Ca-ATPase and the Na,K-ATPase with respect to their effect on the fluorescence changes of the $n X I T C$, dyes, is very clear. This indicates that with respect to ion binding and the position of the binding sites inside the proteins significant differences exist, despite the fact that both pumps are close relatives in the family of P-type ATPases and that it was possible to construct chimeras between both ion pumps, for which at least enzymatic activity could be established (Luckie et al., 1991, 1992; Ishii et al., 1994). The results of the crystal structure of the SR Ca-ATPase (Toyoshima et al., 2000), which revealed the position of the $\mathrm{Ca}^{2+}$ binding sites in the middle of the membrane, and of the electrogenicity of all ion-binding steps, $\mathrm{Ca}^{2+}$ and $\mathrm{H}^{+}$ions (Butscher et al., 1999, Pei- nelt \& Apell, 2002), as well as the similar fluorescence responses of all $n$ XITC dyes on the investigated partial reactions as shown in this paper, fit well together. This structural concept of ion-binding sites that are located in the center of the membrane, is in strong contrast to the observations made with the Na,K-ATPase so far: On the cytoplasmic side, binding of only the third $\mathrm{Na}^{+}$ion is electrogenic, i.e., within the protein dielectric; all other ions, be that $\mathrm{Na}^{+}$or $\mathrm{K}^{+}$, have to bind close to the surface or in wide, water-filled vestibules that are still part of the dielectric protein surface (Goldshlegger et al., 1987, Bahinski et al., 1988, Rakowski et al., 1990, Domaszewicz \& Apell, 1999, Schneeberger \& Apell, 2001). In the experiments presented it could be shown unambiguously that various dyes respond differently on electrogenic $\mathrm{Na}^{+}$binding, which is a strong indication that an ion is being bound within the sensitive length of the styryl chromophores and not in the center of the membrane. This finding proposes a significant difference of structure and placement of the ion binding sites in the Na,K-ATPase and the CaATPase.

We thank Christine Butscher for excellent assistance and Prof. Peter Kroneck for his generous support in performing the EPR measurements. This work was financially supported by the Deutsche Forschungsgemeinschaft (Ap 45/4) and by Bayer AG, Leverkusen.

\section{References}

Apell, H.-J. 1989. Electrogenic properties of the Na,K pump. J. Membrane Biol. 110:103-114

Apell, H.-J., Bersch, B. 1987. Oxonol VI as an optical indicator for membrane potentials in lipid vesicles. Biochim. Biophys. Acta 903:480-494

Apell, H.-J., Karlish, S. J. D. 2001. Functional properties of Na,KATPase, and their structural implications, as detected with biophysical techniques. J. Membrane Biol. 180:1-9

Apell, H.-J., Marcus, M. M., Anner, B.M., Oetliker, H., Läuger, P. 1985. Optical study of active ion transport in lipid vesicles containing reconstituted Na,K-ATPase. J. Membrane Biol. 85:49-63

Apell, H.-J., Schneeberger, A., Sokolov, V.S. 1998. Partial reactions of the Na,K-ATPase: kinetic analysis and transport properties. Acta Physiol Scand. Suppl. 643:235-245

Bahinski, A., Nakao, M., Gadsby, D. C. 1988. Potassium translocation by the $\mathrm{Na}^{+} / \mathrm{K}^{+}$pump is voltage insensitive. Proc. Natl. Acad. Sci. USA 85:3412-3416

Bartlett, G.R. 1959. Colorimetric assay methods for free and phosphorylated glyceric acids. J. Biol. Chem. 234:466-468

Birmes, M.1995. Neuartige membranpotentialsensitive Fluoreszenzfarbstoffe mit Styrylpyridiniumchromophor. Ph.D. thesis, University of Düsseldorf, Germany, pp. 1-248

Borlinghaus, R., Apell, H.-J., Läuger, P. 1987. Fast charge translocations associated with partial reactions of the Na,K-pump: I. Current and voltage transients after photochemical release of ATP. J. Membrane Biol. 97:161-178

Butscher, C., Roudna, M., Apell, H.-J. 1999. Electrogenic partial reactions of the SR-Ca-ATPase investigated by a fluorescence method. J. Membrane Biol. 168:169-181 
Bühler, R., Apell, H.-J. 1995. Sequential potassium binding at the extracellular side of the Na,K-pump. J. Membrane Biol. 145:165-173

Bühler, R., Stürmer, W., Apell, H.-J., Läuger, P. 1991. Charge translocation by the Na,K-pump: I. Kinetics of local field changes studied by time-resolved fluorescence measurements. J. Membrane Biol. 121:141-161

Chattopadhyay, A., London, E. 1987. Parallax method for direct measurement of membrane penetration depth utilizing fluorescence quenching by spin-labeled phospholipids. Biochemistry 26:39-45

Clarke, R.J., Kane, D.J., Apell, H.-J., Roudna, M., Bamberg, E. 1998. Kinetics of $\mathrm{Na}^{+}$-dependent conformational changes of rabbit kidney $\mathrm{Na}^{+}, \mathrm{K}^{+}$-ATPase. Biophys. J. 75:13401353

Domaszewicz, W., Apell, H.-J. 1999. Binding of the third $\mathrm{Na}^{+}$ion to the cytoplasmic side of the Na,K-ATPase is electrogenic. FEBS Lett. 458:241-246

Ehrenberg, B., Meiri, Z., Loew, L.M. 2000. A microsecond kinetic study of the photogenerated membrane potential of bacteriorhodopsin with a fast responding dye. Photochem. Photobiol. 39:199-205

Ephardt, H.E., Fromherz, P. 1989. Fluorescence and photoisomerization of an amphiphilic amino-stilbazolium dye as controlled by the sensitivity of radiationless desactivation to polarity and viscosity. J. Phys. Chem. 93:7717-7725

Fedosova, N.U., Cornelius, F., Klodos, I. 1995. Fluorescent styryl dyes as probes for Na,K-ATPase reaction mechanism: significance of the charge of the hydrophilic moiety of RH dyes. Biochemistry 34:16806-16814

Fendler, K., Grell, E., Haubs, M., Bamberg, E. 1985. Pump currents generated by the purified $\mathrm{Na}^{+} \mathrm{K}^{+}$-ATPase from kidney on black lipid membranes. EMBO J. 4:3079-3085

Fischer, J.K. 1974. Electrochemie an dünnen Schichten. Abhängigkeit der Quantenausbeute einer Photoreaktion vom vibratorischen Anregungszustand. Ph.D. thesis, Zürich,

Fluhler, E., Burnham, V.G., Loew, L.M. 1985. Spectra, membrane binding, and potentiometric responses of new charge shift probes. Biochemistry 24:5749-5755

Friis, P. 1965. The preparation of 3-halopropyl isocyanates and 5,6-dihydro-2-sulphanilamido-4H-1,3-thiazine. Acta Chim. Scand 19:766-774

Fromherz, P., Lambacher, A. 1991. Spectra of voltage-sensitive fluorescence of styryl-dye in neuron membrane. Biochim. Biophys. Acta 1068:149-156

Gadsby, D.C., Rakowski, R.F., de Weer, P. 1993. Extracellular access to the Na,K pump: pathway similar to ion channel. Science 260: 100-103

Goldshlegger, R., Karlish, S.J., Rephaeli, A., Stein, W.D. 1987. The effect of membrane potential on the mammalian sodiumpotassium pump reconstituted into phospholipid vesicles. $J$. Physiol. 387:331-355

Grinvald, A., Fine, A., Farber, I.C, Hildesheim, R. 1983. Fluorescence monitoring of electrical responses from small neurons and their processes. Biophys. J. 42:195-198

Grinvald, A., Salzberg, B.M., Lev-Ram, V., Hildesheim, R. 1987. Optical recording of synaptic potentials from processes of single neurons using intracellular potentiometric dyes. Biophys. J. 51:643-651

Hassner, A., Birnbaum, D., Loew, L.M. 1984. Charge-shift probes of membrane potential synthesis. J. Org. Chem. 49:25462551

Heilmann, C., Brdiczka, D., Nickel, E., Pette, D. 1977. ATPase activities, $\mathrm{Ca}^{2+}$ transport and phosphoprotein formation in sarcoplasmic reticulum subfractions of fast and slow rabbit muscles. Eur. J. Biochem. 81:211-222
Heyse, S., Wuddel, I. Apell, H.-J., Stürmer, W. 1994. Partial reactions of the Na,K-ATPase: determination of rate constants. J. Gen. Physiol. 104:197-240

Hilgemann, D.W. 1994. Channel-like function of the Na,K pump probed at microsecond resolution in giant membrane patches. Science 263:1429-1432

Holmgren, M., Wagg, J., Bezanilla, F., Rakowski, R.F., de Weer, P., Gadsby, D.C. 2000. Three distinct and sequential steps in the release of sodium ions by the $\mathrm{Na}^{+} / \mathrm{K}^{+}$-ATPase. Nature 403:898-901

Ishii, T., Lemas, M.V., Takeyasu, K. 1994. Na+-, ouabain-, $\mathrm{Ca}^{2+}$-, and thapsigargin-sensitive ATPase activity expressed in chimeras between the calcium and the sodium pump $\alpha$ subunits. Proc. Natl. Acad. Sci. USA 91:6103-6107

Jørgensen, P.L. 1974. Isolation of $\left(\mathrm{Na}^{+}\right.$plus $\left.\mathrm{K}^{+}\right)$-ATPase. Methods Enzymol. 32:277-290

Kachel, K., Asuncion-Punzalan, E., London, E. 1998. The location of fluorescence probes with charged groups in model membranes. Biochim. Biophys. Acta 1374:63-76

Kaiser, R.D., London, E. 1998. Location of diphenylhexatriene (DPH) and its derivatives within membranes: comparison of different fluorescence quenching analyses of membrane depth. Biochemistry 37:8180-8190

Karlish, S.J.D. 1980. Characterization of conformational changes in $(\mathrm{Na}, \mathrm{K})$ ATPase labeled with fluorescein at the active site. J. Bioenerg. Biomembr. 12:111-136

Klodos, I. Fedosova, N.U., Cornelius, F. 1997. Fluorescent styryl dyes as probes for Na,K-ATPase reaction. Enzyme source and fluorescence response. Ann. N. Y. Acad. Sci. 834:394-396

Klodos, I. Forbush, B., III. 1988. Rapid conformational changes of the $\mathrm{Na} / \mathrm{K}$ pump revealed by a fluorescent dye RH-160. J. Gen. Physiol. 92:46a

Läuger, P. 1991. Electrogenic Ion Pumps. pp. 1-313 Sinauer Assoc, Sunderland, MA

Läuger, P. and Apell, H.-J. 1989. Electrogenic ion transport. In: Monovalent cations in biological systems. Pasternak, C., editors, pp. 59-102. CRC Press, Boca Raton

Loew, L.M. 1982. Design and characterization of electrochromic membrane probes. J. Biochem. Biophys. Methods 6:243-260

Loew, L.M., Scully, S., Simpson, L., Waggoner, A.S. 1979. Evidence for a charge-shift electrochromic mechanism in a probe of membrane potential. Nature 281:497-499

Loew, L.M., Simpson, L.L. 1981. Charge-shift probes of membrane potential: a probable electrochromic mechanism for $\mathrm{p}$ aminostyrylpyridinium probes on a hemispherical lipid bilayer. Biophys. J. 34:353-365

Luckie, D.B., Boyd, K.L., Takeyasu, K. 1991. Ouabain- and $\mathrm{Ca}^{2+}$ sensitive ATPase activity of chimeric $\mathrm{Na}$ - and Ca-pump molecules. FEBS Letters 281:231-234

Luckie, D.B., Lemas, M.V., Boyd, K.L., Fambrough, D.M., Takeyasu, K. 1992. Molecular dissection of functional domains of the E1E2-ATPase using sodium and calcium pump chimeric molecules. Biophys. J. 62:220-227

Markwell, M.A., Haas, S.M., Bieber, L.L., Tolbert, N.E. 1978. A modification of the Lowry procedure to simplify protein determination in membrane and lipoprotein samples. Anal. Biochem. 87:206-210

Morrison, W.R. 1964. A fast, simple and reliable method for the microdetermination of phosphorus in biological materials. Anal. Biochem. 7:218-224

Müller, W., Windisch, H., Tritthart, H.A. 1986. Fluorescent styryl dyes applied as fast optical probes of cardiac action potential. Eur. Biophys. J. 14:103-111

Peinelt, C., Apell, H.-J. 2002. Kinetics of the $\mathrm{Ca}^{2+}, \mathrm{H}^{+}$and $\mathrm{Mg}^{2+}$ lnteraction with the ion-binding sites of the SR-Ca-ATPase. Biophys. J. 82:170-181 
Pintschovius, J., Fendler, K., Bamberg, E. 1999. Charge translocation by the $\mathrm{Na}^{+} / \mathrm{K}^{+}$-ATPase investigated on solid supported membranes: Cytoplasmic cation binding and release. Biophys. J. 76:827-836

Pratap, P.R., Robinson, J.D. 1993. Rapid kinetic analyses of the $\mathrm{Na}^{+} / \mathrm{K}^{+}$-ATPase distinguish among different criteria for conformational change. Biochim. Biophys. Acta 1151:89-98

Rakowski, R.F. 1993. Charge movement by the Na/K pump in Xenopus oocytes. J. Gen. Physiol. 101:117-144

Rakowski, R.F., Vasilets, L.A., LaTona, J., Schwarz, W. 1990. A negative slope in the current-voltage relationship of the $\mathrm{Na}^{+} /$ $\mathrm{K}^{+}$pump in Xenopus oocytes produced by reduction of external $\left[\mathrm{K}^{+}\right]$. J. Membrane Biol. 121:171-187

Sassaroli, M., Ruonala, M., Virtanen, J., Vauhkonen, M., Somerharju, P. 1995. Transversal distribution of acyl-linked pyrene moieties in liquid-crystalline phosphatidylcholine bilayers. A fluorescence quenching study. Biochemistry 34:88438851

Schneeberger, A., Apell, H.-J. 1999. Ion selectivity of the cytoplasmic binding sites of the Na,K-ATPase: I. Sodium binding is associated with a conformational rearrangement. J. Membrane biol. 168:221-228
Schneeberger, A., Apell, H.-J. 2001. Ion selectivity of the cytoplasmic binding sites of the Na,K-ATPase: II. Competition of various cations. J. Membrane Biol. 179:263-273

Schwartz, A.K., Nagano, M., Nakao, M., Lindenmayer, G.E., Allen, J.C. 1971. The sodium- and potassium-activated adenosinetriphosphatase system. Meth. Pharmacol. 1:361-388

Sokolov, V.S., Apell, H.J., Corrie, J.E., Trentham, D.R. 1998. Fast transient currents in $\mathrm{Na}, \mathrm{K}-\mathrm{ATPase}$ induced by ATP concentration jumps from the P3-[1-(3',5'-dimethoxyphenyl)-2phenyl-2-oxo]ethyl ester of ATP. Biophys. J. 74:2285-2298

Stürmer, W., Apell, H.-J. 1992. Fluorescence study on cardiac glycoside binding to the $\mathrm{Na}, \mathrm{K}$-pump. Ouabain binding is associated with movement of electrical charge. FEBS Lett. 300:1-4

Stürmer, W., Bühler, R., Apell, H.-J., Läuger, P. 1991. Charge translation by the Na,K-pump: II. Ion binding and release at the extracellular face. J. Membrane Biol. 121:163-176

Toyoshima, C., Nakasako, M., Nomura, H., Ogawa, H. 2000. Crystal structure of the calcium pump of sarcoplasmatic reticulum at $2.6 \AA$ resolution. Nature 405:647-655

Wuddel, I. Apell, H.-J. 1995. Electrogenicity of the sodium transport pathway in the Na,K-ATPase probed by charge-pulse experiments. Biophys. J. 69:909-921 